\title{
Erlotinib as second- or third-line treatment in elderly patients with advanced non-small cell lung cancer: Keio Lung Oncology Group Study 001 (KLOG001)
}

\author{
MASAYOSHI MIYAWAKI ${ }^{1,2}$, KATSUHIKO NAOKI ${ }^{1-3}$, SATOSHI YODA $^{1,2}$, SOHEI NAKAYAMA $^{1,2}$, \\ RYOSUKE SATOMI $^{1,2}$, TAKASHI SATO ${ }^{1,2}$, SHINNOSUKE IKEMURA ${ }^{1,2}$, KEIKO OHGINO $^{1,2}$, KOTA ISHIOKA ${ }^{1,2}$, \\ DAISUKE ARAI ${ }^{1,2}$, HO NAMKOONG $^{1,2}$, KENGO OTSUKA $^{1,2}$, MASAKI MIYAZAKI $^{1,2}$, TETSUO TANI ${ }^{1,2}$, \\ AOI KURODA ${ }^{1,2}$, MAKOTO NISHINO ${ }^{1,2}$, HIROYUKI YASUDA ${ }^{1,2}$, ICHIRO KAWADA $^{1,2}$, \\ HIDEFUMI KOH ${ }^{2}$, MORIO NAKAMURA ${ }^{2}$, TAKESHI TERASHIMA ${ }^{2}$, FUMIO SAKAMAKI ${ }^{2}$, \\ KOICHI SAYAMA ${ }^{2}$, TOMOKO BETSUYAKU ${ }^{1,2}$ and KENZO SOEJIMA ${ }^{1,2}$ \\ ${ }^{1}$ Division of Pulmonary Medicine, Department of Medicine, ${ }^{2}$ Keio Lung Oncology Group \\ and ${ }^{3}$ Cancer Center, Keio University School of Medicine, Tokyo 160-8582, Japan
}

Received July 6, 2016; Accepted December 12, 2016

DOI: $10.3892 / \mathrm{mco} .2017 .1154$

\begin{abstract}
The aim of this study was to assess the efficacy and safety of erlotinib, an epidermal growth factor receptor (EGFR) tyrosine kinase inhibitor (TKI), as second- or third-line treatment for elderly Japanese patients with non-small-cell lung cancer (NSCLC). The patients eligible for this phase II trial were aged $\geq 70$ years, had stage III/IV or recurrent NSCLC, and had previously received 1 or 2 chemotherapy regimens that did not include EGFR-TKIs. The patients received erlotinib at a dose of $150 \mathrm{mg} /$ day. The primary endpoint was overall response rate (ORR), and the secondary endpoints were progression-free survival (PFS), overall survival (OS) and toxicity. A total of 38 patients with a median age of 76 years were enrolled. The majority of the patients were men (66\%), had an Eastern Cooperative Oncology Group performance status of $1(58 \%)$, stage IV disease $(66 \%)$ and adenocarcinoma $(74 \%)$. Of the 35 patients, $13(34 \%)$ had tumors with EGFR mutations. The ORR was $26.3 \%$ (95\% confidence interval: $12.1-40.5 \%$ ) and the disease control rate was $47.4 \%$. The median PFS was 3.7 months and the median OS was 17.3 months. The grade 3 adverse events observed included rash (13\%), diarrhea (5\%), interstitial pneumonitis $(5 \%)$, anorexia $(3 \%)$ and gastrointestinal bleeding (3\%). Grade 4 or 5 adverse events were not observed. The median OS did not differ significantly between patients aged $<75$ years ( 14.9 months) and those aged $\geq 75$ years (19.0 months; $\mathrm{P}=0.226$ ). Therefore, erlotinib was found to be
\end{abstract}

Correspondence to: Dr Katsuhiko Naoki, Cancer Center, Keio University School of Medicine, 35 Shinanomachi, Shinjuku-ku, Tokyo 160-8582, Japan

E-mail:knaoki@pg7.so-net.ne.jp

Key words: erlotinib, elderly, non-small-cell lung cancer, phase II trial, epidermal growth factor receptor-tyrosine kinase inhibitor effective and well-tolerated in elderly patients with previously treated NSCLC.

\section{Introduction}

Lung cancer is the leading cause of cancer-related mortality worldwide (1). More than $80 \%$ of all lung cancers are non-small-cell lung cancers (NSCLCs) (2). Platinum-based chemotherapy has been widely accepted as the standard treatment for advanced NSCLC (3) and is appropriate for several patients with lung cancer. However, the use of traditional chemotherapeutic agents, such as platinum, has reached a therapeutic plateau.

Erlotinib, an epidermal growth factor receptor (EGFR) tyrosine kinase inhibitor (TKI), is an effective standard second-line treatment for NSCLC, regardless of EGFR mutation status (4-8). In a previous phase III study (BR.21), erlotinib prolonged overall survival (OS) and progression-free survival (PFS) compared with placebo when used as secondor third-line treatment of NSCLC; the OS was 6.7 and 4.7 months [hazard ratio $(\mathrm{HR})=0.61 ; \mathrm{P}<0.001)$ and the $\mathrm{PFS}$ was 2.2 and 1.8 months $(\mathrm{HR}=0.70 ; \mathrm{P}<0.001)$ in the erlotinib and placebo groups, respectively (4). According to certain reports, erlotinib may also be effective in Japanese patients with previously treated NSCLC, irrespective of their EGFR mutation status $(7,8)$. However, driver oncogene-targeted therapy has met with great success (9-12) and EGFR-TKIs are generally more effective in patients with EGFR mutation-positive NSCLC. Approximately 35-50\% of the NSCLCs in East Asian patients harbor EGFR mutations, which is higher compared with the percentage in Western populations $(13,14)$. To accurately interpret the results of clinical trials, the proportion of patients with EGFR mutation-positive tumors should be taken into account.

Owing to the growing size of the aging population, the number of elderly patients with NSCLC is increasing (15). Although several clinical trials have demonstrated that 
EGFR-TKIs are safe and effective, the safety and efficacy of these drugs specifically in elderly patients remains unclear. Evaluation of these drugs in such patients is necessary given the complications, organ dysfunction and metabolic changes that may accompany aging $(16,17)$. A phase II trial of elderly NSCLC patients receiving erlotinib as second- or third-line treatment was performed by the Keio Lung Oncology Group (KLOG001). This trial included EGFR mutation-positive as well as EGFR mutation-negative tumors and was registered at the UMIN-CTR (study ID: UMIN000001873).

\section{Patients and methods}

Patient eligibility. Patients eligible for this study were aged $\geq 70$ years and had confirmed stage III or IV or postoperative recurrent NSCLC. The patients were previously treated with 1 or 2 chemotherapy regimens that did not include EGFR-TKIs and had at least one measurable lesion according to the Response Evaluation Criteria in Solid Tumors (RECIST), version 1.1 (https://www.eortc.be/Recist/ documents/RECISTGuidelines.pdf). Additional inclusion criteria were Eastern Cooperative Oncology Group (ECOG) performance status (PS) $0-2$, life expectancy $>3$ months and adequate organ function. The main exclusion criteria were major surgery $\leq 4$ weeks, thoracic radiation therapy $\leq 2$ weeks, or chemotherapy $\leq 4$ weeks prior to the trial, and the presence of active double cancer, active infection, interstitial lung disease, symptomatic brain metastasis, or severe comorbidities. This study was approved by the Institutional Review Board at Keio University School of Medicine. All the patients provided written informed consent.

Study design and treatment. This study was a single-arm multi-center phase II trial of second- or third-line erlotinib treatment in elderly patients with NSCLC. The primary endpoint was overall response rate (ORR) and the secondary endpoints were PFS, OS and toxicity. The estimated minimum sample size was 38 , with an $\alpha$ error of 0.05 (one-sided) and a $\beta$ error of 0.2 . The threshold ORR was $10 \%(4,18)$ and the expected ORR was $25 \%$ (19). Assuming that $~ 5 \%$ of patients would not qualify, 40 patients were enrolled. Patients received erlotinib at $150 \mathrm{mg}$ /day until the disease progressed, unacceptable toxicity developed despite dose reduction, or further treatment was refused. If grade 3 or 4 adverse events (AEs) occurred, treatment was withheld for up to 14 days and the dose was reduced. Two dose reductions were permitted per patient (first reduction to $100 \mathrm{mg} / \mathrm{day}$, second reduction to $50 \mathrm{mg} /$ day).

Evaluation. Tumor response was evaluated via computed tomography, magnetic resonance imaging and bone scintigraphy according to RECIST every 4 weeks until treatment cessation. To confirm a complete response (CR) or partial response (PR), a second assessment was conducted 28 days or more after the initial assessment. Stable disease (SD) was defined as disease control (absence of progression) maintained for $\geq 6$ weeks. During this study, patients underwent physical and blood examinations and chest X-rays at least once every 2 weeks. AEs were graded according to the National Cancer Institute Common Terminology Criteria, version 4.0 (https://
evs.nci.nih.gov/ftp1/CTCAE/CTCAE_4.03_2010-06-14_Quick Reference_5x7.pdf). PFS and OS were estimated using the Kaplan-Meier method.

\section{Results}

Patient characteristics. Between April, 2009 and October, 2014, 40 patients were enrolled in this study. A total of 38 patients were eligible for treatment, whereas 2 patients were deemed ineligible owing to priorly receiving 3 chemotherapy regimens, or erlotinib treatment, respectively. The characteristics of the patients are summarized in Table I. The median patient age was 76 years (range, $70-83$ years). The majority of the patients were men $(66 \%)$ and had an ECOG PS of $1(58 \%)$, stage IV disease $(66 \%)$ and adenocarcinoma (76\%). Biopsy samples from 35 patients were screened for gain-of-function EGFR mutations, and mutations were identified in 13 patients (34\%): An exon 19 deletion in 5 patients and an L858R mutation in 8 patients. A total of 35 patients received platinum-based combination chemotherapy and 3 patients received monotherapy as first-line treatment. A total of 16 patients received chemotherapy (including gefitinib treatment in 2 patients) after this trial. A second biopsy was performed in 5 of the 13 patients with EGFR mutation-positive tumors (38\%) and an EGFR T790 M mutation was identified in 3 of those 5 patients $(60 \%)$.

Response. The efficacy results of this study are summarized in Table II. Among the 38 patients in the study, 10 had a PR, 8 had SD and 11 had progressive disease (PD). The ORR for all patients was $26.3 \%$ [95\% confidence interval (CI): $12.1-40.5 \%$ ] and the disease control rate (DCR), defined as $\mathrm{CR}+\mathrm{PR}+\mathrm{SD} /$ total number of patients, was $47.4 \%(95 \% \mathrm{CI}$ : 31.2-63.6\%). Among the 13 patients with EGFR mutations, 7 had a PR, 2 had SD and 2 had PD. The ORR for patients with EGFR mutations was $53.8 \%$ (95\% CI: 26.2-71.4\%) and the DCR was $69.2 \%$ (95\% CI: 43.6-94.8\%). Among the 22 patients with wild-type EGFR, 2 patients had a PR, 5 patients had SD and 9 patients had PD. The ORR for this group was $9.1 \%$ (95\% CI: $0-21.3 \%$ ) and the DCR was $31.8 \%$ (95\% CI: $12.0-51.6 \%)$.

PFS and OS. All 38 patients in the study were included in the survival analysis, and the minimum follow-up time was 7 months. At the time of the analysis, 25 patients had succumbed to the disease, 11 patients remained alive, and 2 patients were lost to follow-up. The median PFS was 3.7 months (95\% CI: 1.1-6.4; Fig. 1A) and the median OS was 17.3 months (95\% CI: 13.3-21.3; Fig. 1B). The median OS was 14.9 months (95\% CI: 9.7-20.1) in patients aged $<75$ years, and 19.0 months (95\% CI: 13.7-24.2) in patients aged $\geq 75$ years (log-rank test, $\mathrm{P}=0.226$; Fig. 2).

The median PFS was 7.8 months (95\% CI: 5.4-10.1) in patients with EGFR mutations and 2.1 months $(95 \% \mathrm{CI}$ : 1.6-2.6) in patients without EGFR mutations (log-rank test, $\mathrm{P}=0.07)$. The median OS was 25.1 months (95\% CI: 20.1-30.0) and 14.9 months (95\% CI: 2.5-27.4), respectively (log-rank test, $\mathrm{P}<0.05)$, and the median post-PD OS was 13.1 months $(95 \%$ CI: 8.0-18.1) and 10.8 months (95\% CI: 0-21.7), respectively (log-rank test, $\mathrm{P}=0.261$ ). 
Table I. Patient characteristics (all, $<75$ years and $\geq 75$ years of age).

\begin{tabular}{|c|c|c|c|}
\hline & \multicolumn{3}{|c|}{ Number of patients } \\
\hline & All & $<75$ years & $\geq 75$ years \\
\hline Total enrolled & 38 & 15 & 23 \\
\hline Age (years), median (range) & $76(70-83)$ & $72(70-74)$ & $79(75-83)$ \\
\hline \multicolumn{4}{|l|}{ Gender } \\
\hline Male & 25 & 9 & 16 \\
\hline Female & 13 & 6 & 7 \\
\hline \multicolumn{4}{|l|}{ Smoking status } \\
\hline Never-smoker & 15 & 5 & 10 \\
\hline Current smoker or ever-smoker & 23 & 10 & 13 \\
\hline Smoking index, median (range) & $750(0-2,600)$ & $750(0-1,800)$ & $520(0-2,600)$ \\
\hline \multicolumn{4}{|l|}{ Performance status } \\
\hline 0 & 13 & 5 & 8 \\
\hline 1 & 22 & 9 & 13 \\
\hline 2 & 3 & 1 & 2 \\
\hline \multicolumn{4}{|l|}{ Stage } \\
\hline IIIA & 6 & 3 & 3 \\
\hline IIIB & 3 & 0 & 3 \\
\hline IV & 25 & 10 & 15 \\
\hline Postoperative recurrence & 4 & 2 & 2 \\
\hline \multicolumn{4}{|l|}{ Histology } \\
\hline Adenocarcinoma & 29 & 13 & 16 \\
\hline Squamous cell carcinoma & 6 & 2 & 4 \\
\hline Non-small-cell carcinoma-NOS & 3 & 0 & 3 \\
\hline \multicolumn{4}{|l|}{$E G F R$ status } \\
\hline Wild-type & 22 & 10 & 12 \\
\hline Exon 19 deletion & 5 & 2 & 3 \\
\hline L858R & 8 & 3 & 5 \\
\hline Unknown/not examined & 3 & 0 & 3 \\
\hline \multicolumn{4}{|l|}{ Prior chemotherapy } \\
\hline One regimen & 27 & 8 & 19 \\
\hline Two regimens & 11 & 7 & 4 \\
\hline \multicolumn{4}{|l|}{ First-line treatment } \\
\hline Platinum doublet & 31 & 10 & 21 \\
\hline Platinum doublet + bevacizumab & 4 & 4 & 0 \\
\hline Monotherapy & 3 & 1 & 2 \\
\hline
\end{tabular}

NOS, not otherwise specified; EGFR, epidermal growth factor receptor.

Toxicity. Erlotinib safety was assessed in all 38 patients in this study, and the AEs observed are summarized in Table III. The main AE was skin rash (76\% of the patients). Grade 3 AEs occurred in 11 patients $(29 \%)$ and included rash $(13 \%)$, diarrhea (5\%), interstitial pneumonitis (5\%), anorexia (3\%) and gastrointestinal (GI) bleeding (3\%). Grade 4 or 5 AEs were not observed. A total of 10 patients $(26 \%)$ discontinued erlotinib due to the following AEs: Rash (3 patients), elevated creatinine level and interstitial pneumonitis (2 patients), and anorexia, diarrhea and GI bleeding (1 patient). The dose of erlotinib was reduced in 10 patients $(26 \%)$ due to rash (7 patients), anorexia (2 patients), or diarrhea (1 patient).

\section{Discussion}

This study investigated the efficacy and safety of erlotinib as second- or third-line treatment for elderly Japanese patients with NSCLC. The ORR, which was the primary endpoint of this study, was $26.3 \%$ (95\% CI: 12.1-40.5\%), which exceeded the threshold ORR (10\%). This percentage (26.3\%) was higher compared with those observed in the BR.21 phase III study of erlotinib as a second- or third-line treatment for NSCLC patients $[8.9 \%$ for all patients $(n=427)$ and $7.6 \%$ for elderly patients (aged $\geq 70$ years, $n=112)](4,20)$. In a phase II trial of erlotinib as second- or third-line treatment for elderly (aged 
Table II. Response assessment.

No. of patients

\begin{tabular}{lcccc}
\cline { 2 - 5 } Type of response & Total & EGFR mutant & EGFR wild-type & Unknown or not examined \\
\hline Complete response & 0 & 0 & 0 & 0 \\
Partial response & 10 & 7 & 2 & 1 \\
Stable disease & 8 & 2 & 5 & 1 \\
Progressive disease & 11 & 2 & 9 & 0 \\
Not evaluable & 9 & 2 & 6 & 3 \\
Total & 38 & 13 & 22 & 3 \\
Response rate $(\%)$ & 26.3 & 53.8 & 31.8 & \\
Disease control rate $(\%)$ & 47.4 & 69.2 & & \\
\hline
\end{tabular}

EGFR, epidermal growth factor receptor.
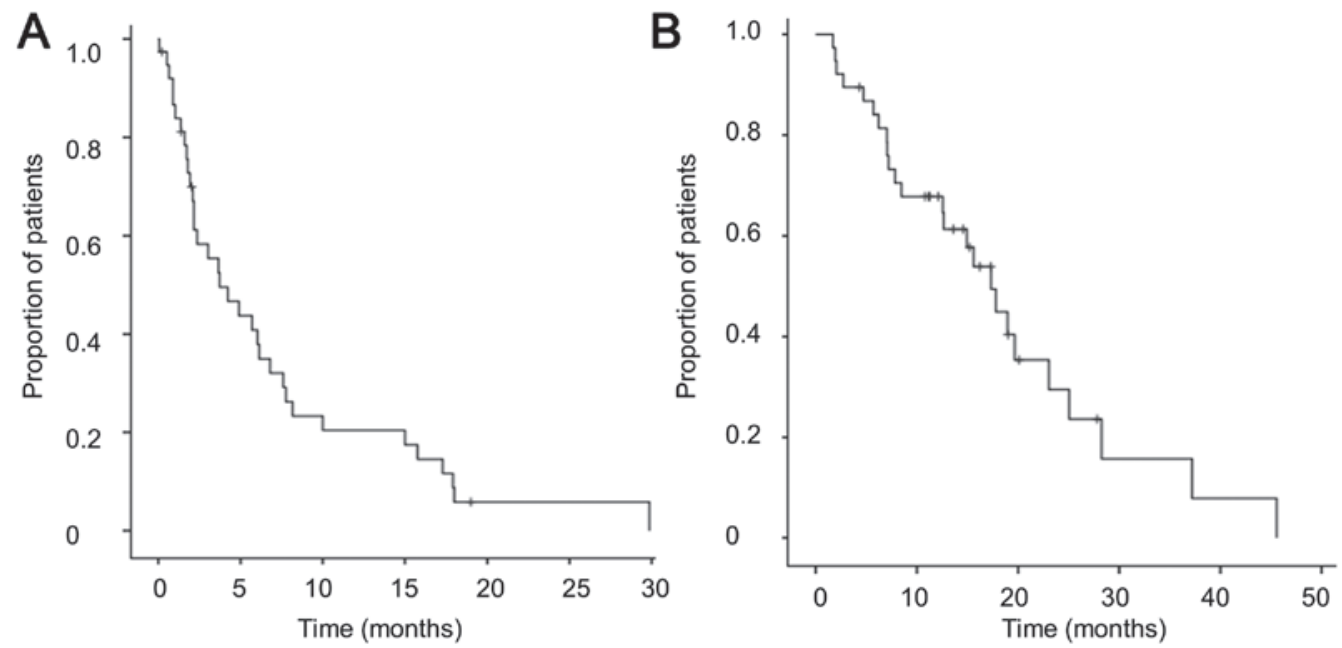

Figure 1. Kaplan-Meier curve analysis for (A) progression-free survival and (B) overall survival in all the patients.

$\geq 65$ years) Italian patients with advanced NSCLC $(n=31)$, the ORR was $16 \%$ (6). We hypothesized that the higher ORR in our study reflects the inclusion of a higher proportion of patients with EGFR mutation-positive tumors. All the patients in our study were Japanese, and tumors with $E G F R$ mutations are most common among Asian patients $(9,13)$. In the BR.21 study, Asian patients $(n=53)$ had a higher ORR compared with patients of other nationalities $(n=374)(18.9$ vs. $7.5 \%$, respectively; $\mathrm{P}=0.02$ ) (4). Other reported ORRs for erlotinib were similar to ours: $28.3 \%$ (95\% CI: $17.5-41.4 \%$ ) in a Japanese phase II study of 60 previously treated NSCLC patients of various ages (7), and 28.3\% (95\% CI: 16.0-43.5) in a Japanese phase II trial of 46 NSCLC patients (21). Both those studies were conducted on populations not selected for EGFR mutations. Overall, the elderly patients in our trial and the Japanese patients of all ages in previous trials had similar ORRs.

In a retrospective analysis of several Japanese studies, the efficacy of erlotinib in terms of survival and tolerability was not lower among elderly compared with younger patients. In a retrospective subgroup analysis of data collected from a population-based observational study, the PFS was similar in elderly (aged $\geq 75$ years, $n=74$ ) and younger (aged $<75$ years, $\mathrm{n}=233$ ) patients (median PFS, 62 vs. 46 days; 95\% CI: 44-80 vs. 35-53 days, respectively; $\mathrm{P}=0.2475$ ) receiving erlotinib for the treatment of NSCLC, regardless of treatment line or EGFR mutation status (22). In that study, OS was also similar between elderly (median, 170 days; 95\% CI: 142-239 days) and younger patients (median, 146 days; 95\% CI: 114-185 days, $\mathrm{P}=0.764$ ). There was also no difference in the incidence of AEs between these groups, and all AEs were manageable. In a phase IV surveillance study of Japanese patients with previously treated NSCLC (the EGFR mutation status was not defined), the median PFS was 65 days for patients aged $<75$ years (95\% CI: 62-68 days), 74 days for patients aged $75-84$ years (95\% CI: 69-82 days), and 72 days for patients aged $\geq 85$ years (95\% CI: $56-93$ days) (23). Moreover, the toxicities were similar in all 3 age groups. In our study, the median OS was 17.3 months and was longer in patients aged $\geq 75$ years compared with that in patients aged $<75$ years (19.0 vs. 14.9 months, respectively), although this difference was not statistically significant $(\mathrm{P}=0.226)$. Erlotinib was considered to be a tolerable and effective treatment for NSCLC patients, irrespective of their age. 
Table III. Adverse events.

\begin{tabular}{lccc}
\hline Toxicities & $\begin{array}{c}\text { All-grade } \\
(\%)\end{array}$ & $\begin{array}{c}\text { Grade } \\
3(\%)\end{array}$ & $\begin{array}{c}\text { Grade } \\
4 / 5(\%)\end{array}$ \\
\hline Rash & $29(76)$ & $5(13)$ & - \\
Stomatitis & $10(26)$ & - & - \\
Diarrhea & $9(23)$ & $2(5)$ & - \\
Fatigue & $2(5)$ & - & - \\
Anorexia & $4(11)$ & $1(3)$ & - \\
Elevated creatinine & $4(11)$ & - & - \\
Elevated bilirubin & $3(8)$ & - & - \\
Elevated hepatic transaminases & $2(5)$ & - & - \\
Gastrointestinal bleeding & $2(5)$ & $1(3)$ & - \\
Pneumonitis & $2(5)$ & - & - \\
Interstitial pneumonitis & $2(5)$ & $2(5)$ & - \\
\hline
\end{tabular}

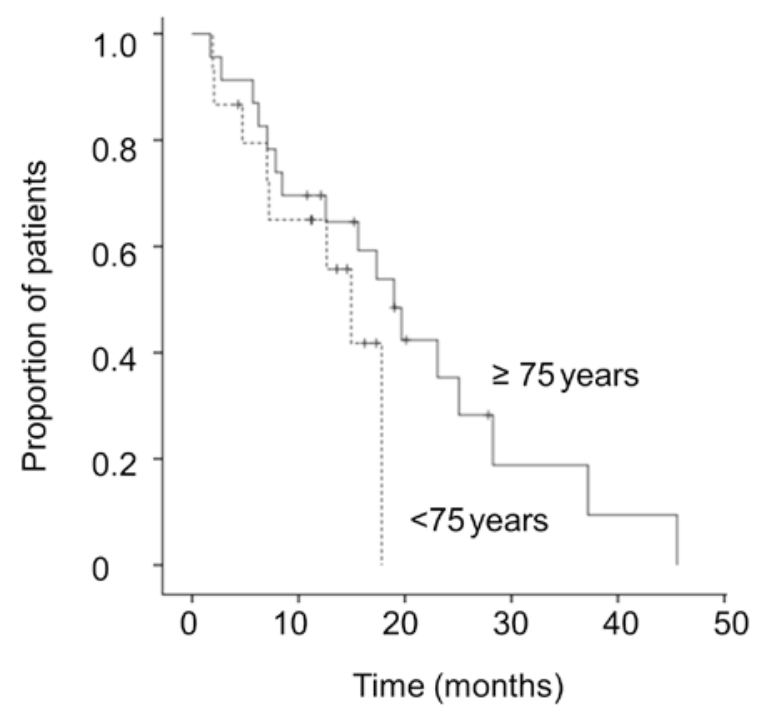

Figure 2. Kaplan-Meier curves for overall survival by age group (age $<75$ vs. $\geq 75$ years).

In our study, the OS was significantly longer in patients with $E G F R$ mutation-positive tumors compared with that in patients with $E G F R$ mutation-negative tumors. The PFS and post-PD OS were also longer, although the difference was not statistically significantly. To date, 2 prospective trials have enrolled elderly NSCLC patients according to their EGFR mutation status: One was a phase II study of elderly patients (aged $\geq 75$ years) with EGFR mutation-positive NSCLCs who received erlotinib as first- or second-line treatment $(n=32)$. In that study, the ORR was $56.3 \%$ (95\% CI: 39.4-72.0\%) and the median PFS was 15.5 months (95\% CI: 11.2-not reached) (24). The second prospective clinical trial examined elderly patients (aged $\geq 70$ years) with $E G F R$ mutation-negative tumors in the second- and third-line settings (25). This small phase II trial $(\mathrm{n}=16)$ reported an ORR of $0 \%$ (95\% CI: 0-17.1\%), a median PFS time of 1.7 months (95\% CI: 1.3-2.2 months) and a median OS time of 7.2 months (95\% CI: 5.6-8.7 months); however, it was terminated early as a phase III trial (26) found that docetaxel was superior to erlotinib in terms of PFS and ORR in patients with $E G F R$ mutation-negative tumors. The results of the two prospective studies cited above $(24,25)$ suggested that erlotinib should be administered only to patients with EGFR mutations, even in the second- and third-line settings. However, in our study, 2 of the 22 patients with EGFR mutation-negative tumors, and 1 of the 3 patients with tumors in which the EGFR mutation status was unknown, responded to erlotinib (ORR=12.0\%; $\mathrm{DCR}=36.0 \%)$. These responses suggest that erlotinib remains a viable second- or third-line treatment option for elderly patients with NSCLC.

In the BR.21 study, elderly patients (aged $\geq 70$ years) had more severe (grade 3 or 4 ) AEs compared with younger patients (aged $<70$ years) ( 35 vs. $18 \%$, respectively; $\mathrm{P}<0.001)(20)$. In our study, 11 patients (29\%) had grade 3 AEs, most of which were managed via dose reductions. Grade 4 or 5 AEs were not observed. Two patients had grade 3 interstitial pneumonitis and were treated with corticosteroid therapy. The frequency of AEs in our study was not higher compared with the previously reported frequencies $(28.1-35 \%)(20,24)$. Therefore, erlotinib appears to be well-tolerated in elderly patients with previously treated NSCLC.

A limitation of our study was its small sample size, which precluded us from drawing definitive conclusions from the results of the main analysis and subset analysis. However, our study recruited a larger number of patients compared with previous prospective studies of elderly NSCLC patients in Japan $(24,25)$. The definition of elderly patients varies across trials. For the present trial, age $\geq 70$ years was used as an inclusion criterion, which was standard at that time $(20,25)$. In accordance with the current standard definition for 'elderly' NSCLC patients $(22,23), \geq 75$ and $<75$ years of age was used in our comparison of 'latter-stage elderly' and 'early elderly' patients, respectively. There were no significant differences in response, survival, or toxicity between these age groups.

In conclusion, our phase II study demonstrated the efficacy and safety of erlotinib as second- and third-line treatment for elderly patients with NSCLC, regardless of whether they were 'early elderly' or 'latter-stage elderly' patients.

\section{Acknowledgements}

The authors would like to thank the patients, their families and all the members of the Keio Lung Oncology Group for their participation and support in this study. TB discloses that her university received research grants from Chugai Pharmaceutical.

\section{References}

1. Torre LA, Bray F, Siegel RL, Ferlay J, Lortet-Tieulent J and Jemal A: Global cancer statistics, 2012. CA Cancer J Clin 65: 87-108, 2015

2. Molina JR, Yang P, Cassivi SD, Schild SE and Adjei AA: Non-small cell lung cancer: Epidemiology, risk factors, treatment, and survivorship. Mayo Clin Proc 83: 584-594, 2008.

3. Schiller JH, Harrington D, Belani CP, Langer C, Sandler A, Krook J, Zhu J and Johnson DH; Eastern Cooperative Oncology Group: Comparison of four chemotherapy regimens for advanced non-small-cell lung cancer. N Engl J Med 346: 92-98, 2002.

4. Shepherd FA, Rodrigues Pereira J, Ciuleanu T, Ciuleanu T, Tan EH, Hirsh V, Thongprasert S, Campos D, Maoleekoonpiroj S, Smylie M, et al: Erlotinib in previously treated non-small-cell lung cancer. N Engl J Med 353: 123-132, 2005. 
5. Yasuda H, Park E, Yun CH, Sng NJ, Lucena-Araujo AR, Yeo WL Huberman MS, Cohen DW, Nakayama S, Ishioka K, et al: Structural, biochemical and clinical characterization of epidermal growth factor receptor (EGFR) exon 20 insertion mutations in lung cancer. Sci Transl Med 5: 216ra177, 2013.

6. Rossi D, Dennetta D, Ugolini M, Catalano V, Alessandroni P, Giordani P, Baldelli AM, Casadei V, Graziano F and Luzi Fedeli S: Activity and safety of erlotinib as second- and third-line treatment in elderly patients with advanced non-small cell lung cancer: A phase II trial. Target Oncol 5: 231-235, 2010.

7. Kubota K, Nishiwaki Y, Tamura T, Nakagawa K, Matsui K, Watanabe K, Hida T, Kawahara M, Katakami N, Takeda K, et al: Efficacy and safety of erlotinib monotherapy for Japanese patients with advanced non-small cell lung cancer: A phase II study. J Thorac Oncol 3: 1439-1445, 2008.

8. Matsuura S, Inui N, Ozawa Y, Nakamura Y, Toyoshima M, Yasuda K, Yamada T, Shirai T, Suganuma H, Yokomura K, et al: Phase II study of erlotinib as third-line monotherapy in patients with advanced non-small-cell lung cancer without epidermal growth factor receptor mutations. Jpn J Clin Oncol 41: 959-963, 2011.

9. Paez JG, Jänne PA, Lee JC, Tracy S, Greulich H, Gabriel S, Herman P, Kaye FJ, Lindeman N, Boggon TJ, et al: EGFR mutations in lung cancer: Correlation with clinical response to gefitinib therapy. Science 304: 1497-1500, 2004.

10. Imielinski M, Berger AH, Hammerman PS, Hernandez B, Pugh TJ, Hodis E, Cho J, Suh J, Capelletti M, Sivachenko A, et al: Mapping the hallmarks of lung adenocarcinoma with massively parallel sequencing. Cell 150: 1107-1120, 2012.

11. Pao W and Girard N: New driver mutations in non-small-cell lung cancer. Lancet Oncol 12: 175-180, 2011.

12. Soda M, Choi YL, Enomoto M, Takada S, Yamashita Y, Ishikawa S, Fujiwara S, Watanabe H, Kurashina K, Hatanaka H, et al: Identification of the transforming EML4-ALK fusion gene in non-small-cell lung cancer. Nature 448: 561-566, 2007.

13. Serizawa M, Koh Y, Kenmotsu H, Isaka M, Murakami H, Akamatsu H,Mori K, Abe M, Hayashi I, Taira T, et al: Assessment of mutational profile of Japanese lung adenocarcinoma patients by multitarget assays: A prospective, single-institute study. Cancer 120: 1471-1481, 2014.

14. Naoki K, Soejima K, Okamoto H, Hamamoto J, Hida N, Nakachi I, Yasuda H, Nakayama S, Yoda S, Satomi R, et al: The PCR-invader method (structure-specific 5' nuclease-based method), a sensitive method for detecting EGFR gene mutations in lung cancer specimens; comparison with direct sequencing. Int J Clin Oncol 16: 335-344, 2011.

15. Thakkar JP, McCarthy BJ and Villano JL: Age-specific cancer incidence rates increase through the oldest age groups. Am J Med Sci 348: 65-70, 2014.

16. Ershler WB and Longo DL: Aging and cancer: Issues of basic and clinical science. J Natl Cancer Inst 89: 1489-1497, 1997.

17. Gridelli $\mathrm{C}$ and Shepherd FA: Chemotherapy for elderly patients with non-small cell lung cancer: A review of the evidence. Chest 128: 947-957, 2005.
18. Jackman DM, Yeap BY, Lindeman NI, Fidias P, Rabin MS, Temel J, Skarin AT, Meyerson M, Holmes AJ, Borras AM, et al: Phase II clinical trial of chemotherapy-naive patients $>$ or $=$ 70 years of age treated with erlotinib for advanced non-small-cell lung cancer. J Clin Oncol 25: 760-766, 2007.

19. Maruyama R, Nishiwaki Y, Tamura T, Yamamoto N, Tsuboi M, Nakagawa K, Shinkai T, Negoro S, Imamura F, Eguchi K, et al: Phase III study, V-15-32, of gefitinib versus docetaxel in previously treated Japanese patients with non-small-cell lung cancer. J Clin Oncol 26: 4244-4252, 2008.

20. Wheatley-Price P, Ding K, Seymour L, Clark GM and Shepherd FA: Erlotinib for advanced non-small-cell lung cancer in the elderly: An analysis of the national cancer institute of canada clinical trials group study BR.21. J Clin Oncol 26: 2350-2357, 2008.

21. Takahashi T, Yamamoto N, Nukiwa T, Mori K, Tsuboi M, Horai T, Masuda N, Eguchi K, Mitsudomi T, Yokota S, et al: Phase II study of erlotinib in Japanese patients with advanced non-small cell lung cancer. Anticancer Res 30: 557-563, 2010.

22. Kurishima K, Satoh H, Kaburagi T, Nishimura Y, Shinohara Y, Inagaki M, Endo T, Saito T, Hayashihara K, Hizawa N, et al: Erlotinib for elderly patients with non-small-cell lung cancer: Subset analysis from a population-based observational study by the Ibaraki Thoracic Integrative (POSITIVE) Research Group. Mol Clin Oncol 1: 828-832, 2013.

23. Yoshioka H, Komuta K, Imamura $F$, Kudoh S, Seki A and Fukuoka M: Efficacy and safety of erlotinib in elderly patients in the phase IV POLARSTAR surveillance study of Japanese patients with non-small-cell lung cancer. Lung Cancer 86: 201-206, 2014

24. Inoue $Y$, Inui N, Asada K, Karayama M, Matsuda H, Yokomura K, Koshimizu N, Imokawa S, Yamada T, Shirai T, et al: Phase II study of erlotinib in elderly patients with non-small cell lung cancer harboring epidermal growth factor receptor mutations. Cancer Chemother Pharmacol 76: 155-161, 2015.

25. Minemura H, Yokouchi H, Azuma K, Hirai K, Sekine S, Oshima K, Kanazawa K, Tanino Y, Inokoshi Y, Ishii T, et al: A phase II trial of erlotinib monotherapy for pretreated elderly patients with advanced EGFR wild-type non-small cell lung cancer. BMC Res Notes 8: 220, 2015.

26. Kawaguchi T, Ando M, Asami K, Okano Y, Fukuda M, Nakagawa H, Ibata H, Kozuki T, Endo T, Tamura A, et al: Randomized phase III trial of erlotinib versus docetaxel as second- or third-line therapy in patients with advanced non-small-cell lung cancer: Docetaxel and Erlotinib Lung Cancer Trial (DELTA). J Clin Oncol 32: 1902-1908, 2014. 